\title{
Void structure of $\mathrm{O}$ ions in the inner magnetosphere observed by the Van Allen Probes
}

\section{AUTHOR(S):}

Nakayama, Y.; Ebihara, Y.; Ohtani, S.; Gkioulidou, M.; Takahashi, K.; Kistler, L. M.; Tanaka, T.

\section{CITATION:}

Nakayama, Y.... [et all. Void structure of $\mathrm{O}$ ions in the inner magnetosphere observed by the Van Allen Probes. Journal of Geophysical Research: Space Physics 2016, 121(12): 11698-11713

\section{ISSUE DATE:}

2016-12

URL:

http://hdl.handle.net/2433/267740

\section{RIGHT:}

(c) 2016. American Geophysical Union. All Rights Reserved.; The full-text file will be made open to the public on 03 May 2017 in accordance with publisher's 'Terms and Conditions for Self-Archiving'. 


\section{Journal of Geophysical Research: Space Physics}

\section{RESEARCH ARTICLE \\ 10.1002/2016JA023013 \\ Void structure of $\mathrm{O}^{+}$ions in the inner magnetosphere observed by the Van Allen Probes}

Key Points:

- We report a new type of $\mathrm{O}^{+}$ion spectral structure named "void structure"

- Our simulation successfully reproduced the void structure

- Generation mechanisms of the void structure are investigated by using the numerical simulation

Supporting Information:

- Supporting Information S1

- Figure S1

Correspondence to:

Y. Nakayama,

yohei_nakayama@rish.kyoto-u.ac.jp

\section{Citation:}

Nakayama, Y., Y. Ebihara, S. Ohtani, M. Gkioulidou, K. Takahashi, L. M. Kistler, and T. Tanaka (2016), Void structure of $\mathrm{O}^{+}$ions in the inner magnetosphere observed by the Van Allen Probes,

J. Geophys. Res. Space Physics, 121, $11,698-11,713$, doi:10.1002/ 2016JA023013.

Received 7 JUN 2016 Accepted 24 OCT 2016

Accepted article online 3 NOV 2016 Published online 3 DEC 2016

\author{
Y. Nakayama' ${ }^{1}$, Y. Ebihara ${ }^{1}$, S. Ohtani ${ }^{2}$, M. Gkioulidou' ${ }^{2}$, K. Takahashi ${ }^{2}$, L. M. Kistler ${ }^{3}$, and T. Tanaka ${ }^{4}$ \\ ${ }^{1}$ Research Institute for Sustainable Humanosphere, Kyoto University, Kyoto, Japan, ${ }^{2} J o h n s$ Hopkins University Applied \\ Physics Laboratory, Laurel, Maryland, USA, ${ }^{3}$ Space Science Center, University of New Hampshire, Durham, New Hampshire, \\ USA, ${ }^{4}$ International Center for Space Weather Science and Education, Kyushu University, Fukuoka, Japan
}

Abstract The Van Allen Probes Helium Oxygen Proton Electron instrument observed a new type of enhancement of $\mathrm{O}^{+}$ions in the inner magnetosphere during substorms. As the satellite moved outward in the premidnight sector, the flux of the $\mathrm{O}^{+}$ions with energy $\sim 10 \mathrm{keV}$ appeared first in the energy-time spectrograms. Then, the enhancement of the flux spread toward high and low energies. The enhanced flux of the $\mathrm{O}^{+}$ions with the highest energy remained, whereas the flux of the ions with lower energy vanished near apogee, forming what we call the void structure. The structure cannot be found in the $\mathrm{H}^{+}$spectrogram. We studied the generation mechanism of this structure by using numerical simulation. We traced the trajectories of $\mathrm{O}^{+}$ions in the electric and magnetic fields from the global magnetohydrodynamics simulation and calculated the flux of $\mathrm{O}^{+}$ions in the inner magnetosphere in accordance with the Liouville theorem. The simulated spectrograms are well consistent with the ones observed by Van Allen Probes. We suggest the following processes. (1) When magnetic reconnection starts, an intensive equatorward and tailward plasma flow appears in the plasma lobe. (2) The flow transports plasma from the lobe to the plasma sheet where the radius of curvature of the magnetic field line is small. (3) The intensive dawn-dusk electric field transports the $\mathrm{O}^{+}$ions earthward and accelerates them nonadiabatically to an energy threshold; (4) the void structure appears at energies below the threshold.

\section{Introduction}

Sudden enhancement of the energy flux of ions is one of the common features in the inner magnetosphere during substorms [e.g., Mcllwain, 1974; Konradi et al., 1975; Belian et al., 1978; Ejiri, 1978; Ejiri et al., 1980; Mauk and Meng, 1983; Daglis and Axford, 1996; Fu et al., 2002; Mitchell et al., 2003; Ohtani et al., 2007; Keika et al., 2010, 2013; Gkioulidou et al., 2014, 2015]. The flux enhancement can be explained by acceleration and transport of particles from the nightside plasma sheet [e.g., Delcourt, 2002; Fok et al., 2006; AshourAbdalla et al., 2009; Peroomian et al., 2011; Birn et al., 2013]. During the substorm expansion phase, the plasmasheet ions are accelerated and transported into the inner magnetosphere due to an intense dawn-dusk electric field [e.g., Li et al., 1998; Zaharia et al., 2000; Ashour-Abdalla et al., 2011; Birn et al., 2013; Ebihara and Tanaka, 2013]. After the transport, the energetic ions become a major constituent of the ring current [Gkioulidou et al., 2014].

Various in situ observations of particle injections show several structures in energy-time spectrograms including the dispersionless structure [Akasohu, 1977; Mauk and Meng, 1983; Reeves et al., 1991; Li et al., 1998; Fu et al., 2002; Keika et al., 2010; Gkioulidou et al., 2015], the nose structure [e.g., Smith and Hoffman, 1974; Ejiri, 1978; Ejiri et al., 1980], and the wedge-like dispersion structure [Yamauchi et al., 1996; Ebihara et al., 2001; Yamauchi et al., 2006; Ebihara et al., 2008]. Recently, Zhang et al. [2015] reported a new structure by using Van Allen Probes observations, termed "trunk-like structure," which is characterized by the decrease of the energy of the flux of $\mathrm{O}^{+}$ions as the spacecraft moves earthward.

Numerical simulations have been adopted in various studies as a useful tool for understanding specific structures in particle flux energy-time spectrograms found by in situ observations. Ejiri [1978] and Ejiri et al. [1980] have calculated the trajectories of ions along with their travel times. They showed that ions at a certain energy penetrate deeper and faster into the inner region, resulting in the nose structure of newly injected ions. Ebihara et al. [2001] performed particle drift simulation to investigate the generation mechanism of the wedge-like dispersion structure observed by Viking. They showed that the dispersion structure can be due to the energy-dependent drift motion of ions from a short-lived plasma flow channel that exists in the 
near-Earth tail. Zhang et al. [2015] used a numerical simulation to trace the particle drift backward in time to understand a trunk-like structure and concluded that the trunk-like structure is likely caused by a gap in the nightside ion source or greatly enhanced impulsive electric fields.

The purpose of this study is to report the characteristics of a new type of structure "void structure," which is observed by the Helium Oxygen Proton Electron (HOPE) instrument of the Van Allen Probes and understand its generation mechanisms by using the numerical simulation introduced by Nakayama et al. [2015].

\section{Van Allen Probes Observation}

The Van Allen Probes mission is designed for understanding the energetic plasma environment in the inner magnetosphere. The two Van Allen Probes spacecraft (Probe A and Probe B) are in nearly identical orbits, with a perigee altitude of $\sim 600 \mathrm{~km}$, an apogee geocentric distance of $5.8 R_{E}$, and an orbital inclination of $10^{\circ}$ [Mauk et al., 2013]. The HOPE instrument onboard Van Allen Probes measures the fluxes of helium, oxygen, protons, and electrons with an energy range from a few eV to $\sim 50 \mathrm{keV}$ with energy resolution $<20 \%$ [Kessel et al., 2013, Funsten et al., 2013].

\subsection{Observation of the Void Structure}

Figure 1 shows an overview of energy-time spectrograms of $\mathrm{H}^{+}$ions and $\mathrm{O}^{+}$ions observed by HOPE on the two satellites on 7 March 2013. Figure 1a shows the time evolution of the SML index, which is similar to the conventional $A L$ index but is derived from the SuperMAG data set [Gjerloev, 2012]; the original data are collected by stations distributed worldwide, and therefore, the $S M L$ index tends to be a better measure of the westward electrojet if its peak intensity takes place in a longitudinally limited area or off the typical latitudinal range of the auroral oval. The SML sharply decreased to $\sim-200 \mathrm{nT}$ at 07:50 UT and to $\sim-270 \mathrm{nT}$ at 11:10 UT as shown in Figure 1a. It is likely that at least two substorms took place. Figures $1 \mathrm{f}$ and $1 \mathrm{~g}$ show the trajectories of the satellite drawn in the SM coordinates. During this interval, the apogees of the Van Allen Probes were located at $5.8 R_{E}$ and at $\sim 1 \mathrm{~h}$ in magnetic local time (MLT) and Probe B was ahead of Probe $A$ by $\sim 2.5 \mathrm{~h}$. Figures $1 \mathrm{~b}$ and $1 \mathrm{c}$ (Figures $1 \mathrm{~d}$ and $1 \mathrm{e}$ ) show the energy-time spectrograms of the omnidirectional flux of $\mathrm{H}^{+}$and $\mathrm{O}^{+}$ions observed by HOPE A (HOPE B), respectively. On the outbound pass of Probe $A$, at 10:40 UT, the $\mathrm{H}^{+}$flux started to increase first at $\sim 10 \mathrm{keV}$ at $\mathrm{L}=\sim 5.3$ (at $\sim 5 \mathrm{keV}$ at $\mathrm{L}=\sim 5.2$ for inbound) and the flux increase spread to both higher and lower energies with increasing $L$-value. The reverse pattern was seen on the inbound pass. This structure is known as the nose structure. The structure was not perfectly symmetric with respect to the apogee. This probably means that the structure depends on MLT as well as on universal time [Ejiri et al., 1980]. The $\mathrm{O}^{+}$flux showed a similar nose structure at $\mathrm{L}=\sim 5.3$ on the outbound pass and at $\mathrm{L}=\sim 5.2$ on the inbound pass. However, the observed $\mathrm{O}^{+}$flux was significantly low at energies below $\sim 8 \mathrm{keV}$ near apogee. Only the outer envelope of the nose structure is observed in the energy-time spectrogram. About $2.5 \mathrm{~h}$ ahead of Probe $\mathrm{A}$, Probe B proceeded almost the same trajectory and observed a similar structure. Again, the $\mathrm{O}^{+}$flux near apogee was depleted below $\sim 5 \mathrm{keV}$. The shape of the dispersion is somewhat different from that observed by Probe $\mathrm{A}$. The difference probably can be attributed to a temporal variation rather than a spatial variation. Hereinafter, we call the structure a void structure. As will be discussed later, the void structure is different from the structures previously reported.

Figure 2a shows an example of the energy- $\mathrm{L}$ spectrogram of $\mathrm{O}^{+}$flux measured by Probe $\mathrm{A}$ during a different event (an interval between 01:30 UT and 06:00 UT on 12 April 2013). During this event, the apogees of the Van Allen Probes were located at $\sim 5.9 R_{E}$ and at 00:00 MLT. A substorm took place on its outbound pass as determined by the $S M L$ index (Figure $S 1 \mathrm{~g}$ in the supporting information). A clear nose structure was observed at $\mathrm{L}>4.6$, and the $\mathrm{O}^{+}$flux below $\sim 10 \mathrm{keV}$ depleted at $\mathrm{L}>5.6(>\sim 01: 00 \mathrm{MLT})$. In order to specify the characteristics of the void structure quantitatively, we introduced two parameters for this study as shown in Figure 2 b, an earthward boundary and a threshold energy of the void structure. For the observation (inbound pass of the event on 11 April 2013), the earthward boundary of the void structure was located at $L=\sim 5.6$, and the threshold energy of the void structure was $\sim 10 \mathrm{keV}$ at $\mathrm{L}=\sim 5.9$.

\subsection{Analysis of Van Allen Probes Data}

We surveyed data from HOPE on Van Allen Probes acquired between 1 January 2013 and 30 May 2013 during which the apogees of the two spacecraft were located on the nightside. Nine void structures were 
07-Mar-13

(a)

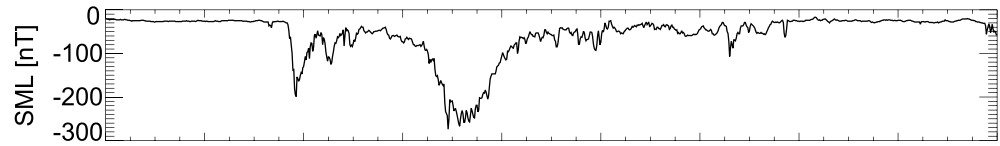

(b)

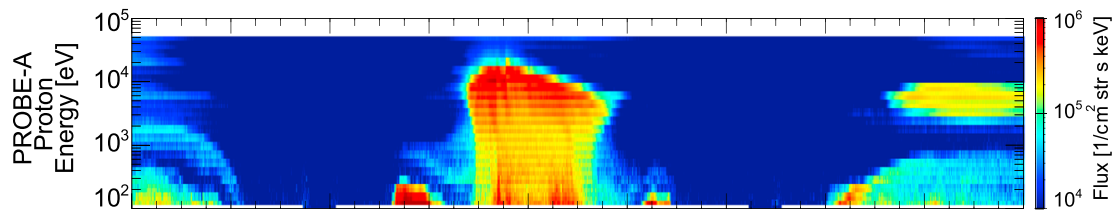

(c)

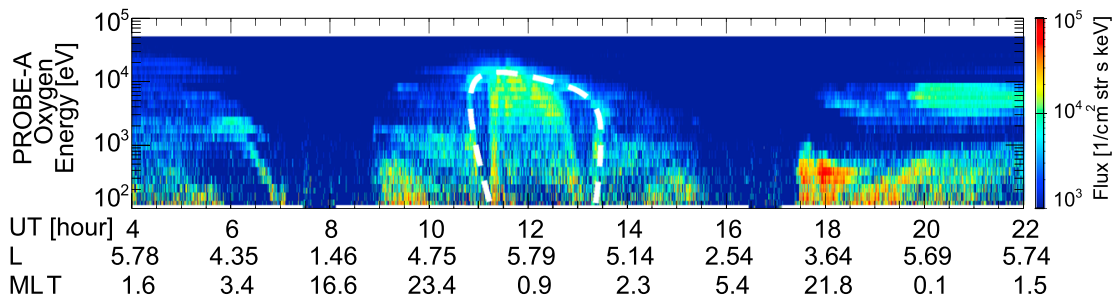

(d)

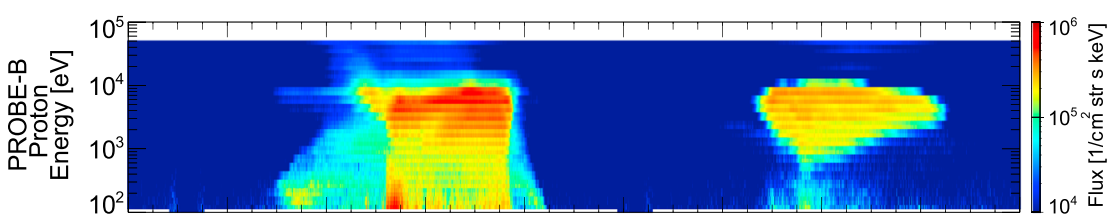

(e)

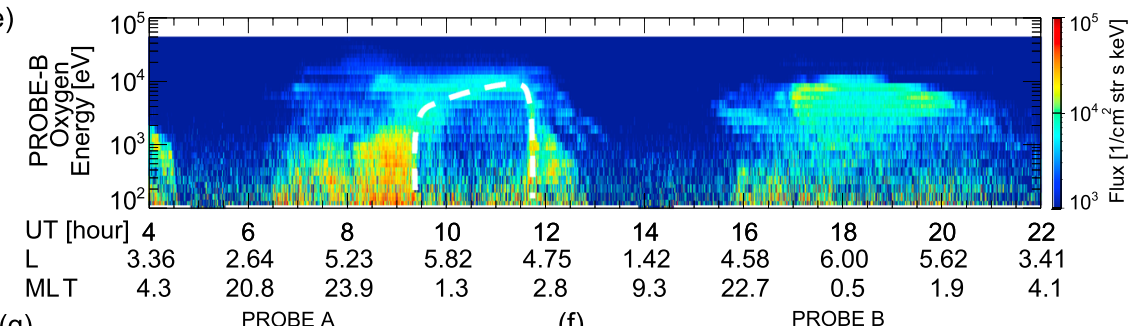

(g)

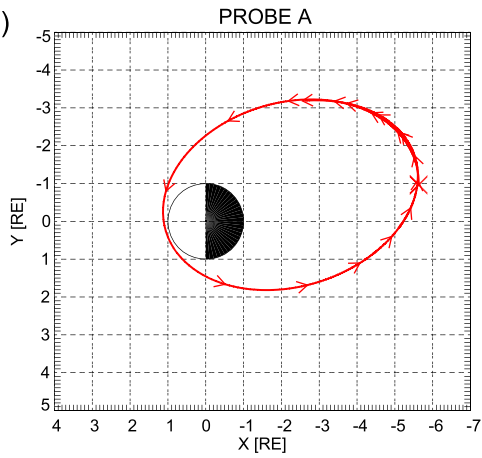

(f)
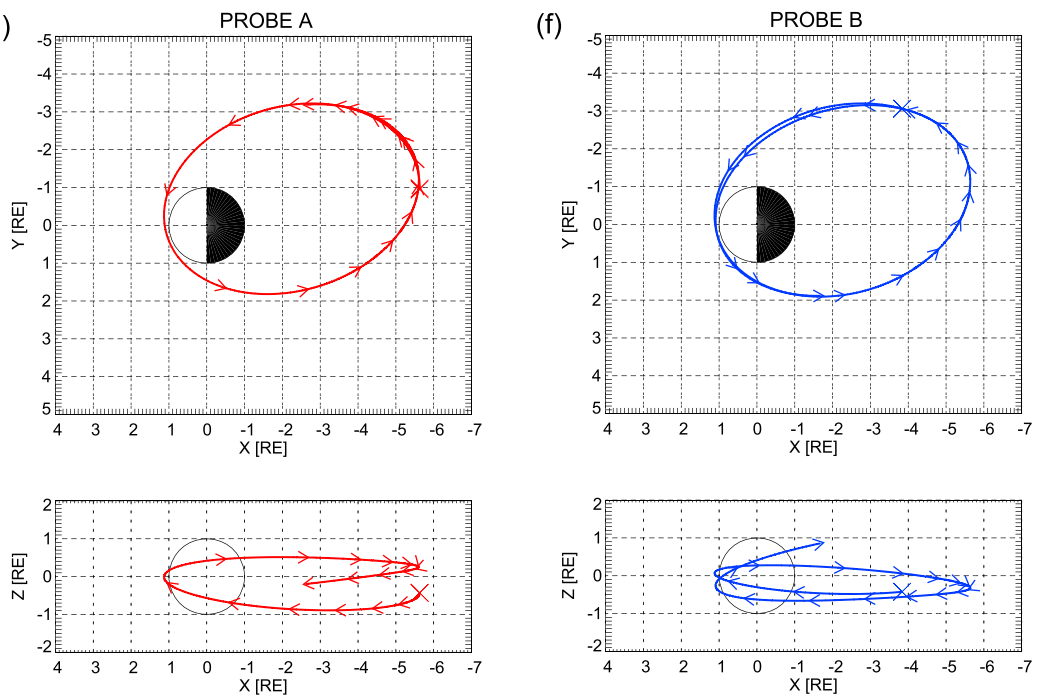

Figure 1. (a) $S M L$ index (similar index to $A L$ index), (b-e) energy-time spectrograms of omnidirectional energy flux of $\mathrm{H}^{+}$ and $\mathrm{O}^{+}$from HOPE on Probe A and Probe B on 3 March 2013, and ( $\mathrm{f}$ and $\mathrm{g}$ ) orbits of Probe A and Probe B in the SM coordinate system: $x-y$ plane in the top row and $x-z$ plane in the bottom row. Enhancements of high-energy particles are observed in the inner magnetosphere associated with small substorms. 
(a) 11-Apr-13

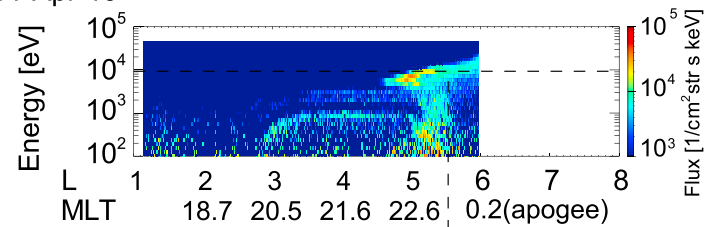

(b)

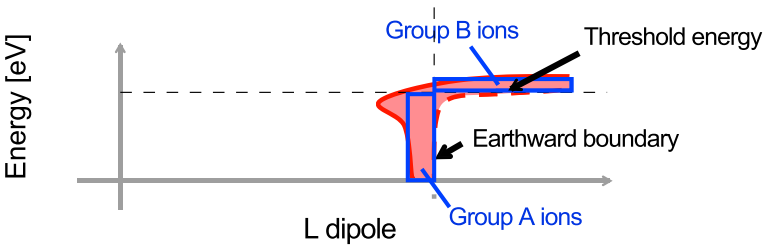

Figure 2. (a) Energy-L spectrogram of $\mathrm{O}^{+}$flux acquired by Probe $A$ during the interval between 01:30 UT and 06:00 UT on 12 April 2013. (b) Schematic drawing of the spectrogram explaining the void structure studied in this paper. We call ions in the earthward most edge of this spectrogram as Group A and ions in the upper edge of this spectrogram as Group B. A faint line-shaped spectrum $(L=3 \sim 5)$ of low-energy particles seen around $1 \mathrm{keV}$ is outside the scope of this paper.

void structures were observed. The color indicates the flux in a specific energy range. To clearly identify the earthward boundary of the void structure, we chose the energy ranging from $\sim 0.7 \mathrm{keV}$ to $\sim 4.8 \mathrm{keV}$. The energy was kept constant through one revolution of orbit. For the $\mathrm{H}^{+}$ions observed on 11 April 2013, the flux sharply increased around $x=-4.4 R_{E}, y=2.3 R_{E}(\mathrm{~L}=\sim 5.0)$ on the outbound pass (solid arrow) and decreased around $x=-4.6 R_{E}, y=-2.3 R_{E}(\mathrm{~L}=\sim 5.1)$ on the inbound pass (solid arrow). For the $\mathrm{O}^{+}$ions, however, the flux showed a sharp decrease (open arrow) soon after the sharp increase (solid arrow) on the outbound pass. The same happened on the inbound pass. These banded structures appeared when the satellite passed through the earthward boundary of the void structure, which is schematically shown in Figure 2b. For the observation on 11 April 2013, the earthward boundaries of the void structure are located at $L=\sim 5.6$ on the outbound and inbound passes.

We investigated the energy that satisfies the following criterion

$$
\mathrm{df} / \mathrm{d}\left(\log _{10} K\right)>10^{3}, K>10^{3}
$$

where $f$ is the flux in $1 / \mathrm{cm}^{2} \operatorname{str} s \mathrm{keV}$ and $K$ is the kinetic energy in eV. Figure 4 is the same as Figure 3 , but the colors indicate the maximum energy that satisfies equation (1). If we did not identify any energy that meets the criterion, we did not plot dots at the position. The open arrows in Figures $4 \mathrm{a}$ and $4 \mathrm{~b}$ set at the same positions as in Figures $3 e$ and $3 f$ show the earthward boundaries of the void structure observed on 11 April 2013. Around the earthward boundaries of the void structure, the energy sharply increased to $\sim 10 \mathrm{keV}$. The energy outside the earthward boundaries may be equal to the threshold energy of the void structure. For the observation on 11 April 2013, the threshold energy of the void structure distributed $\sim 10 \mathrm{keV}$.

Table 1. Event List of the Void Structure

\begin{tabular}{lc} 
& Date \\
\hline Event 1 & $01-\mathrm{Feb}-13$ \\
Event 2 & $05-\mathrm{Feb}-13$ \\
Event 3 & $10-\mathrm{Feb}-13$ \\
Event 4 & $26-\mathrm{Feb}-13$ \\
Event 5 & $07-\mathrm{Mar}-13$ \\
Event 6 & $09-\mathrm{Mar}-13$ \\
Event 7 & $10-\mathrm{Apr}-13$ \\
Event 8 & $11-\mathrm{Apr}-13$ \\
Event 9 & $14-\mathrm{May}-13$ \\
\hline
\end{tabular}

\section{Numerical Simulation}

We adopted the same simulation introduced by Nakayama et al. [2015], in which we traced the trajectories of $\mathrm{O}^{+}$ions by using the electric and magnetic fields generated by a global MHD simulation [Tanaka et al., 2010; Ebihara and Tanaka, 2013]. The global MHD simulation developed by Tanaka et al. [2010] and Tanaka [2015] successfully demonstrated several important features 


\section{AGU. Journal of Geophysical Research: Space Physics 10.1002/2016JA023013}

(a)

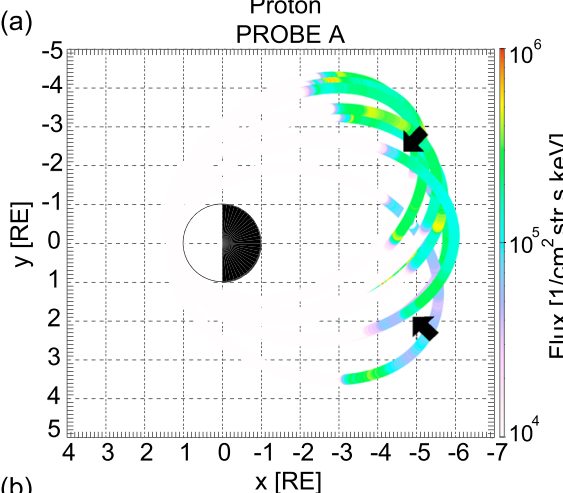

(b)

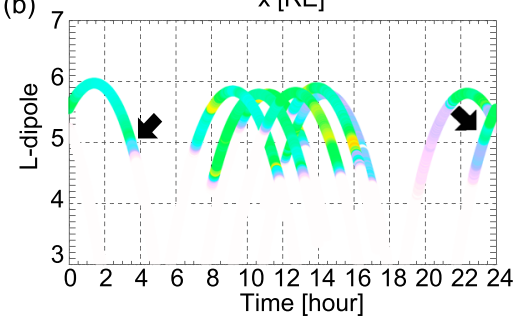

(e)
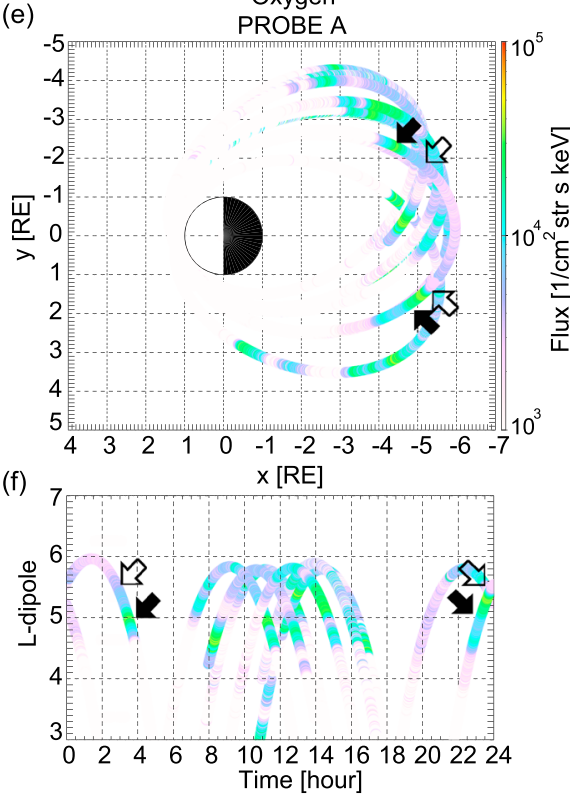

(c)

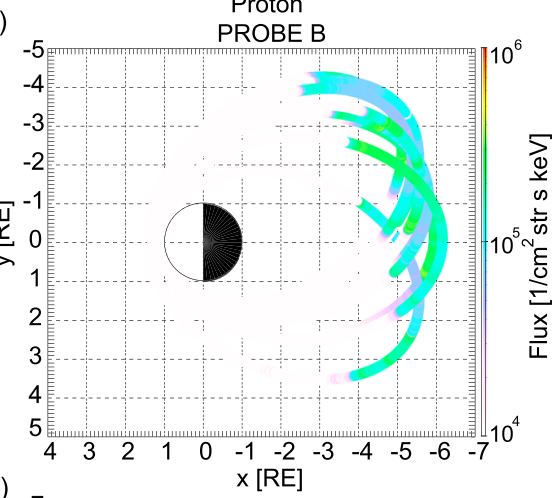

(d)

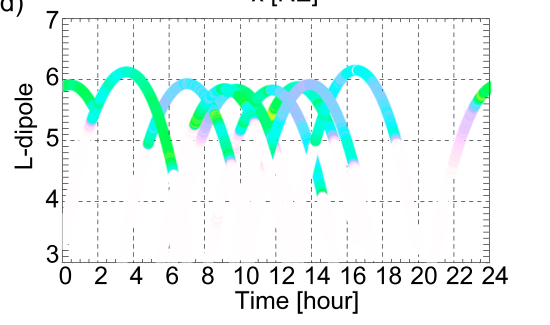

(g)

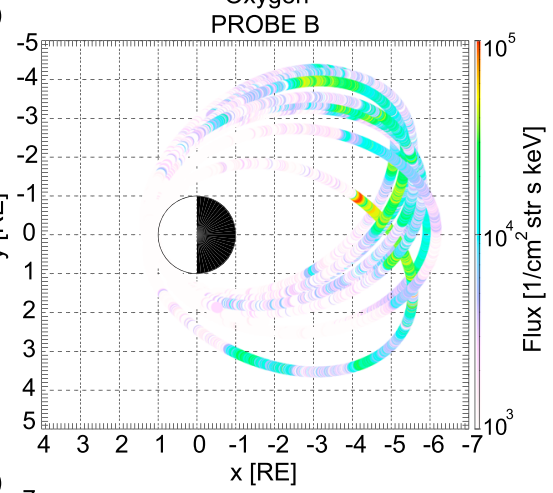

(h)

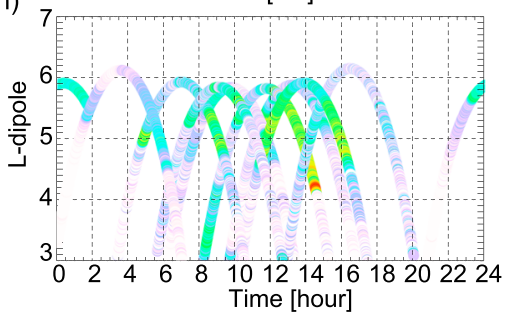

Figure 3. (a-d) Trajectories of Probe A and Probe $B$ in $x-y$ plane in the SM coordinate and L-value as a function of time during the nine substorm events. The color indicates the flux of $\mathrm{H}^{+}$ions at energy between $\sim 0.7 \mathrm{keV}$ and $\sim 4.8 \mathrm{keV}$. (e-h) Same as Figures $3 \mathrm{a}-3 \mathrm{~d}$ but for $\mathrm{O}^{+}$ions.

that emerge during a substorm such as the current wedge [Tanaka et al., 2010], energetic particle injection [Ebihara and Tanaka, 2013], westward traveling surge [Tanaka, 2015; Ebihara and Tanaka, 2015], and the magnetic disturbance at auroral latitudes [Tanaka et al., 2010] as well as magnetic equator [Ebihara et al., 2014]. In this study, we utilized the same global MHD simulation result performed by Ebihara and Tanaka [2013] and Nakayama et al. [2015] in which the solar wind speed was held constant at $500 \mathrm{~km} / \mathrm{s}$, and interplanetary magnetic field (IMF) turned from $(0,2.5,5.0)$ to $(0,2.5,-5.0) \mathrm{nT}$. The result showed that the calculated $A L$ index decreased to $\sim-800 \mathrm{nT}$ [Ebihara and Tanaka, 2013]. Just after the $A L$ decrease, the dawn to dusk electric field is enhanced to $\sim 13 \mathrm{mV} / \mathrm{m}$ at $>\sim 6 R_{E}$ in longitudinally narrow regions in the premidnight and postmidnight sector [Nakayama et al., 2015]. In the present study, the onset of substorm expansion phase is defined as the moment at which the $A L$ index suddenly decreases, and hereinafter referred to as $T=0$. 

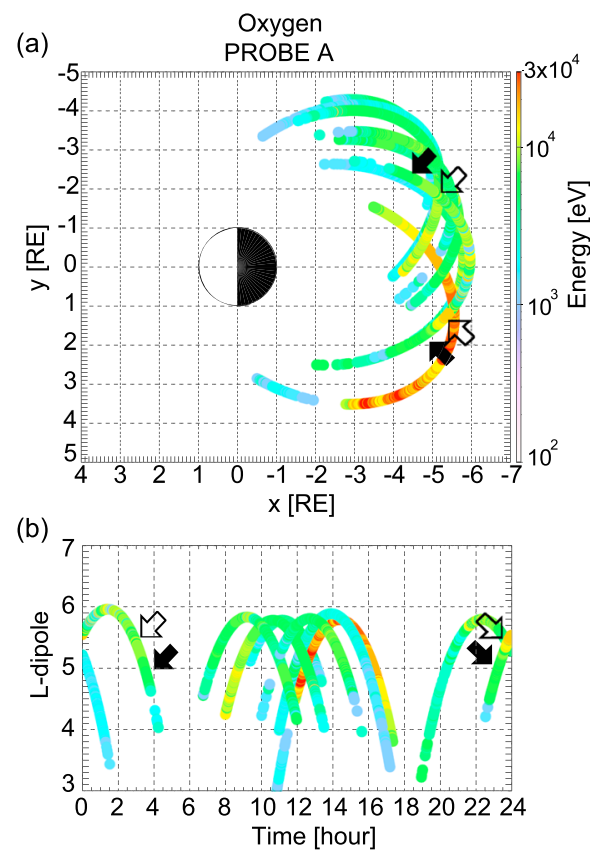

(c)

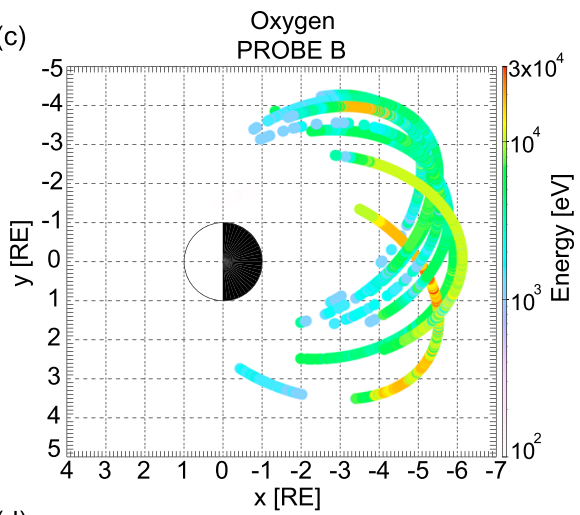

(d)

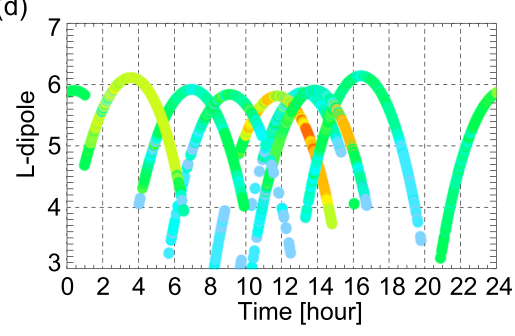

Figure 4. (a-d) Same as Figures 3e-3h but the colors indicate the energy that satisfies equation (1).

In the test particle simulation, $\mathrm{O}^{+}$ions were launched from off-equatorial positions with initial energies from $1 \mathrm{eV}$ to $1 \mathrm{keV}$ at every integer minute during $T=-20$ to $15 \mathrm{~min}$. Those $\mathrm{O}^{+}$ions were launched at $Z= \pm 2 R_{E}$ ranging from $X=-7$ to $-17 R_{E}$ and from $Y=-10$ to $10 R_{E}$. The real number of particles $\Delta N$ is calculated assuming a drifting Kappa distribution in the source region given by as

$$
f_{i}=\frac{n}{\pi^{3 / 2} \theta^{3}} \frac{\Gamma(\kappa+1)}{\kappa^{3 / 2} \Gamma(\kappa-1 / 2)}\left(1+\frac{\left(\mathbf{v}-\mathbf{V}_{\mathrm{MHD}}\right)^{2}}{\kappa \theta^{2}}\right)^{-(\kappa+1)}
$$

and

$$
\theta=\left(\frac{2 \kappa-3}{\kappa} \frac{k T}{m}\right)^{1 / 2}
$$

where $n, \kappa, k, m, \mathbf{v}, T$, and $\mathbf{V}_{\mathrm{MHD}}$ are the density, the spectral index, the Boltzmann constant, the mass of particle, the velocity of particle, the temperature, and the bulk velocity of plasma given by the MHD simulation. In this study, we assumed that cold $\mathrm{O}^{+}$ions (temperature is $10 \mathrm{eV}$ ) are continuously supplied from the ionosphere to the lobe region. This process is observed by many studies [e.g., Vaisberg et al., 1995; Moore et al., 1997] and assumed as a main source of the ring current $\mathrm{O}^{+}$ions [Fok et al., 2006]. On the other hand, an impulsive supply of energetic $\mathrm{O}^{+}$ions (a few keV) from the nightside aurora region [e.g., Gazey et al., 1996; Sauvaud et al., 2004] was not assumed in this study. As initial parameters of the cold ions, we used $n=0.1 \mathrm{~cm}^{-3}, \kappa=4.5$, and $k T=10 \mathrm{eV}$. After the tracing, we resembled the flux of $\mathrm{O}^{+}$ion in the inner magnetosphere by accumulating the real number of the $\mathrm{O}^{+}$ions falling into a small bin in configuration space and velocity space. The numerical simulation successfully reconstructed the $\mathrm{O}^{+}$flux enhancement with a dispersion-less structure in the midnight region, a dispersed structure in the dusk region, and a nose structure around the inner edge of the plasmasheet at dusk region. Nakayama et al. [2015] have shown that most of the $\mathrm{O}^{+}$ions undergo nonadiabatic motion and that the kinetic energy of some ions increases to a level on the order of $100 \mathrm{keV}$. See Nakayama et al. [2015] for more details.

\subsection{Energy-L Spectrogram}

Figure $5 \mathrm{a}$ is the same figure as Figure $2 \mathrm{a}$. Figures $5 \mathrm{~b}-5 \mathrm{e}$ show energy- $\mathrm{L}$ spectrograms of the simulated $\mathrm{O}^{+}$ion fluxes at 00:00 MLT and 22:00 MLT in the equatorial plane. We defined that the $L$ value and the radial distance are same in the equatorial plane. Note that the energy scale of the simulation plots is shifted by an order of magnitude from the observational plot. At 00:00 MLT, the energy of the ions increases with increasing L. The 
(a)

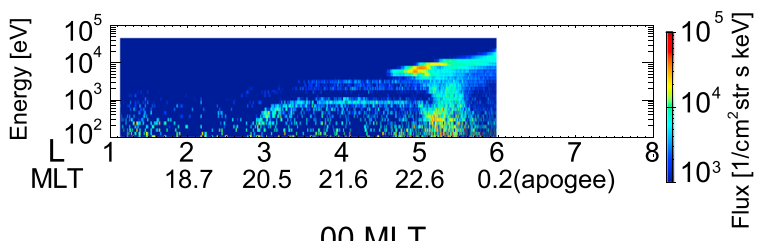

(b)

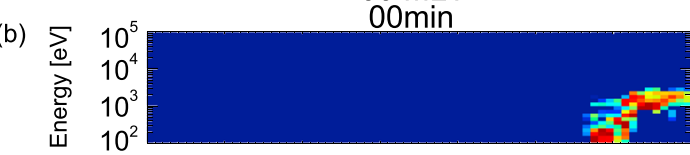

(c)

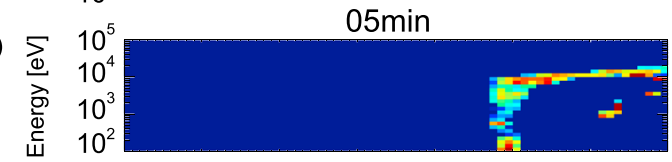

(d)

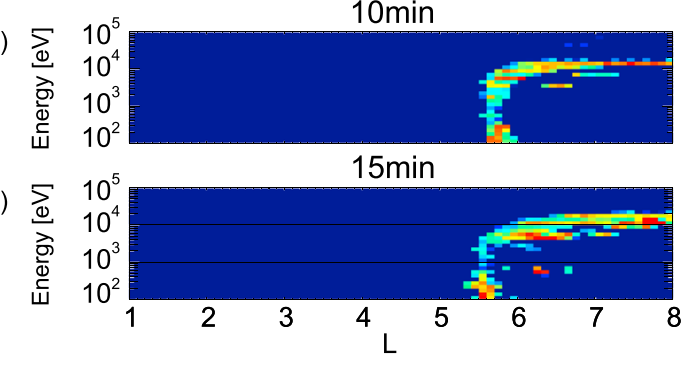

$22 \mathrm{MLT}$

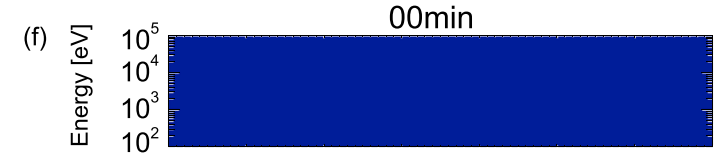

(g)

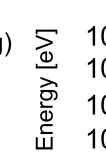

(h)

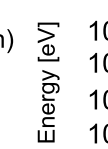

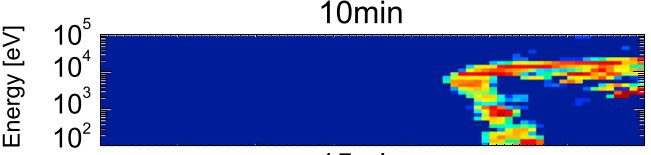

(i)

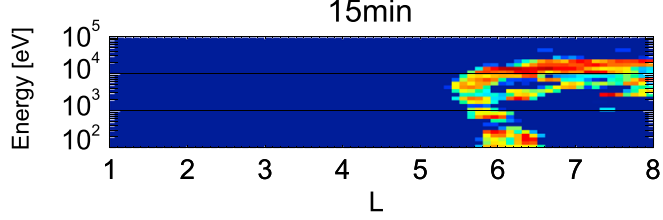

Figure 5. (a) Reproduction of Figure 2a. (b-e) Energy-L spectrograms of the simulated $\mathrm{O}^{+}$ions at 00:00 MLT in the equatorial plane. (f-i) Energy- $\mathrm{L}$ spectrograms of the simulated $\mathrm{O}^{+}$ions at 22:00 MLT in the equatorial plane. Time in minute $(\mathrm{min})$ is elapsed time after the substorm onset. structure that appears in the energy$L$ spectrograms reproduces the void structure shown in Figure 2. In particular, the structure has a clear earthward boundary and the threshold energy can be defined. The earthward boundary moved earthward as time progresses. The threshold energy increases between $T=0 \mathrm{~min}$ and $5 \mathrm{~min}$. After $T=5 \mathrm{~min}$, the threshold energy remains almost constant or slightly decreases. At $T=15 \mathrm{~min}$, for example, the earthward boundary of the void structure is located at $L=5.8$ and the threshold energy of the void structure is $\sim 30 \mathrm{keV}$ at $\mathrm{L}=6.0$. At 22:00 MLT, the ions with energy from $\sim 20 \mathrm{keV}$ to $\sim 60 \mathrm{keV}$ appear first with increasing $R$. The spectral shape is morphologically consistent with that shown in Figure 5a. Although our simulation successfully shows general features of the void structure, the threshold energy is a bit higher than the observed values. This is because solar wind parameters and IMF conditions are different from the observation. In the simulated substorm, the minimum $A L$ is $\sim-800 \mathrm{nT}$ which is negatively much larger $(\sim-290 \mathrm{nT})$ than the event on 11 April 2013. During the larger substorm, the more intensive dawn to dusk electric field can be generated and results in the higher threshold energy in the calculated energy-L spectrogram as shown in Figure 5. Our purpose is to understand a general feature of the void structure emerging during substorms, and reproducing exactly that the observation is beyond the scope of this study.

\subsection{Spatial Distribution of the Threshold Energy of the Void Structure}

We also calculated the threshold energy of the simulated void structure by means of the same procedure described above. Figure 6 shows the spatial distribution of the threshold energy of the void structure. The region where threshold energy of the void structure is not identified is filled with white. In general, the void region is widely distributed in the nightside region. The spatial peak of the threshold energy of the void structure increases with time and reaches $\sim 200 \mathrm{keV}$ at $x=-7 R_{E}, y=2 R_{E}$ at $T=15 \mathrm{~min}$.

\subsection{Formation of the Void Structure}

To investigate the generation mechanisms of the void structure, we divided ions in the void structure into two groups. Group A resides at the earthward edge of the envelope of the void structure. Group B resides 
(a)

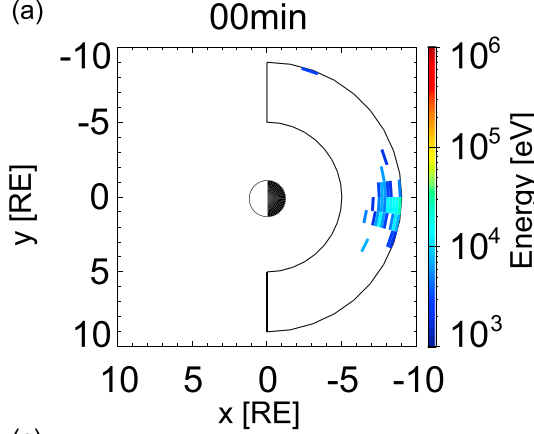

(c)

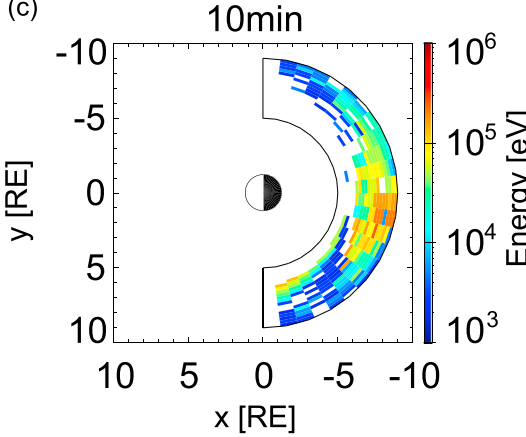

(b)

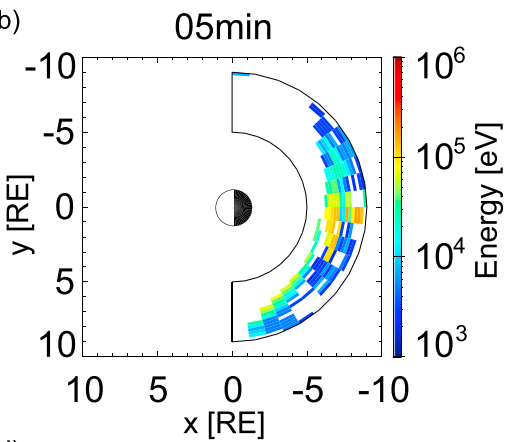

(d)

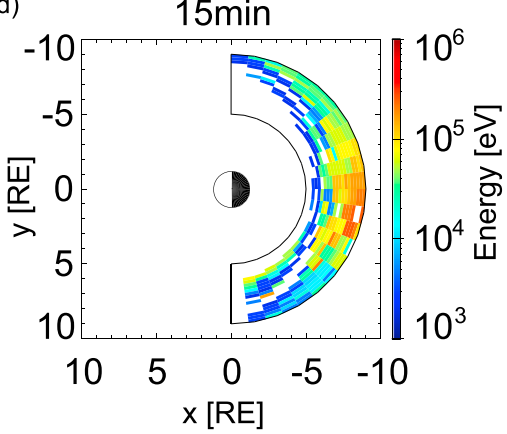

Figure 6. (a-d) Spatial distribution in the $x$-y plane of the threshold energy of the simulated void structure at $T=0,5,10,15 \mathrm{~min}$.

at the upper edge of the envelope of the void structure. The groups are schematically drawn in Figure 2. As a representative of Group A, we chose the ions with energies below $20 \mathrm{keV}$ and located at $\mathrm{L}=5.6$, at 00:00 MLT and at $T=15 \mathrm{~min}$. As a representative of Group B, we chose the ions with energies between $100 \mathrm{keV}$ and $200 \mathrm{keV}$ and at $\mathrm{L}=8.0$, at 00:00 MLT and at $T=15 \mathrm{~min}$. We did not choose ions around the earthward boundary as a representative of the Group $B$ because generation mechanisms of the ions located around a turning point are unclear. Figure 7a shows the flux as a function of the time of departure from the source for the Group $A$ ions and Group B ions, and Figure $7 \mathrm{~b}$ shows the flux as a function of the initial position of the ions in the source plane in the northern hemisphere. The vertical axis of Figure $7 \mathrm{a}$ and the color in Figure $7 \mathrm{~b}$ show the flux values mapped from that of Group A and B ions. Most of the Group A ions departed the source region 10 min before the substorm onset. The initial positions are between $x=-9 R_{E}$ and $x=-17 R_{E}$ in the midnight region. Most of the Group B ions departed the source region after the substorm onset between $T=\sim-4 \mathrm{~min}$ and $T=\sim 11 \mathrm{~min}$. The initial positions are distributed in the postmidnight region ( $x=-8 R_{E}$ to $-16 R_{E} y=\sim-6 R_{E}$ ).

In Figure 8, the black arrows show the MHD plasma flow velocities in the $x-z$ plane $\left(V_{x z}\right)$ at $y=0 R_{E}$ and $y=-6$ $R_{E}$. The black and red lines indicate the magnetic field lines projected into the $x-z$ plane and the location of the $\mathrm{O}^{+}$source plane set by Nakayama et al. [2015]. As mentioned above, the initial distribution function of the $\mathrm{O}^{+}$ ions in the source plane is given by a drifting Kappa distribution in this simulation. This means that $\mathrm{O}^{+}$ions are launched with the thermal velocity in the frame of the MHD plasma flow velocity ( $\mathbf{V}_{M H D}$ in equation (2)). For Group A ions, from Figure 8a, the average of the $x-z$ component of $\mathbf{V}_{\mathrm{MHD}}\left(V_{x z}\right)$ at the source positions $\left(z= \pm 2 R_{E}\right)$ is $\sim 10 \mathrm{~km} / \mathrm{s}$ that is equivalent to $\sim 10 \mathrm{eV}$ for $\mathrm{O}^{+}$ion. On the other hand, the temperature of the launched ions ( $k T$ in equation (2)) is assumed to be $10 \mathrm{eV}$ in the simulation model. This indicates that the thermal speed $\left(\theta\right.$ in equation (2)) is comparable to $V_{x z}$ for Group $A$ ions when they are launched.

After the substorm onset, at $y=-6 R_{E}$ and $z= \pm 2 R_{E}$, the flow is directed equatorward and tailward with a significant intensification (Figure 8d). This (1) equatorward and (2) tailward flow enhancement at the offequatorial position is due to the following: (1) The formation of the near-Earth neutral line $\left(x=\sim-11 R_{E}\right.$ in Figure $8 \mathrm{~d}$ ) results in the large difference of magnetic field strength between equator $\left(z=\sim 0 R_{E}\right)$ and off-equator $\left(|z|=\sim 1 R_{E}\right)$. The difference of magnetic field strength increases the magnetic pressure force accelerating the background plasma toward the equatorial plane. (2) After the substorm onset, the high-pressure region $\left(x=\sim-7 R_{E}\right.$ ) expands antiequatorward across the magnetic field line, results in the pressure gradient force along magnetic field lines accelerating the background plasma toward the tail [Yao et al., 2015]. Another 
(a)
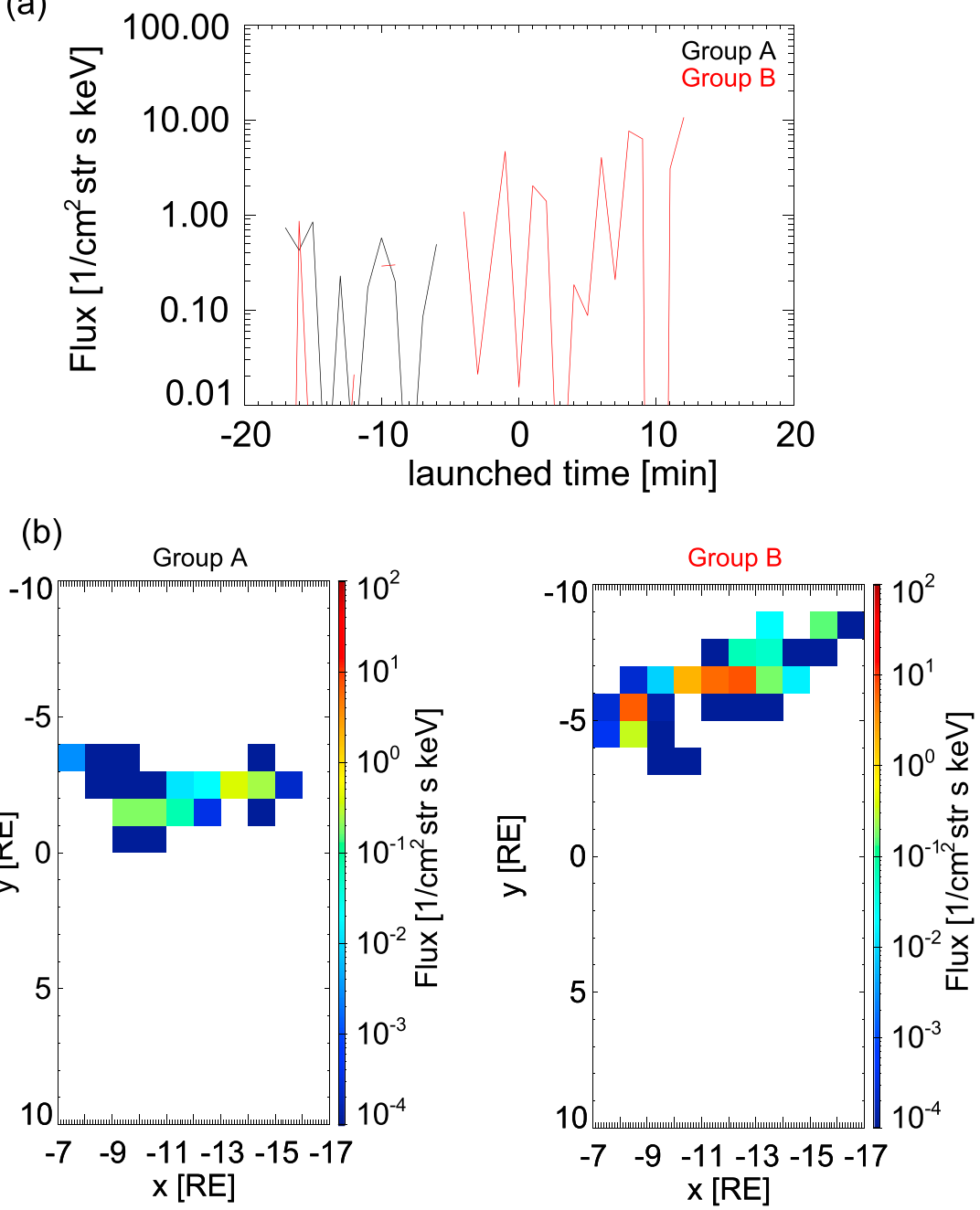

Figure 7. (a) Flux as a function of launched time of the Group A ions (black line) and Group B ions (red line), and (b) distribution of launched position of the ions in the source plane in the northern hemisphere for Group A ions (left) and for Group $B$ ions (right).

feature to be noted is the reversal of the flow direction (Figure 8d). This flow pattern has been investigated in Yao et al. [2015] by using a same global MHD simulation. They show that the flow is directed earthward in the high-pressure region and tailward in the low-pressure region. $\left|V_{x z}\right|$ is greater than $\sim 100 \mathrm{~km} / \mathrm{s}$ at $y=-6 R_{E}$ and $z= \pm 2 R_{E}$ which is equivalent to $>\sim 1 \mathrm{keV}$ for $\mathrm{O}^{+}$ion. For Group $\mathrm{B}$ ions, because the temperature at the source position is also assumed to be $k T=10 \mathrm{eV}, V_{x z}$ is much larger than the thermal speed $\theta$ at the launch position. This strong flow brings most of the lobe $\mathrm{O}^{+}$ions to the plasmasheet $\left(x<-10 R_{E}\right)$ where the radius of curvature of the magnetic field line is small and the dawn to dusk electric field is enhanced.

Figure 9 shows one typical trajectory of Group A ions. Figure 9a shows the trajectory of a sample ion in the equatorial plane together with the black contours indicating the $Y$ component of the electric field $E_{y}$ at $T=0 \mathrm{~min}$. Figure $9 \mathrm{~b}$ shows the trajectory of the ion in the noon-meridian plane, and the black lines show the magnetic field lines. The ion departed at $(-16,-1,2) R_{E}$ at $T=-10 \mathrm{~min}$ and reached $(\sim-8.5, \sim 0.5,0)$ $R_{E}$ at $T=\sim 3 \mathrm{~min}$. When the ion departed, $\mathbf{V}_{\mathrm{MHD}}$ is $(26,2,-8) \mathrm{km} / \mathrm{s}$ at the launched postion, which is equivalent to $\sim 60 \mathrm{eV}$ and the ion has the kinetic energy of $\sim 30 \mathrm{eV}$ in the frame of the flow. After the launch, the ion heads earthward and moves toward the equatorial plane. The ion passes through the equatorial plane just before the substorm onset. Then it is accelerated to $\sim 12 \mathrm{keV}$ (Figure 9c) and transported to the inner region after a subtorm onset. The magnetic moment fluctuates around $100 \mathrm{eV} / \mathrm{nT}$ during the acceleration, which suggests that the ion is adiabatically accelerated (Figure 9d). 


\section{AGU Journal of Geophysical Research: Space Physics 10.1002/2016JA023013}
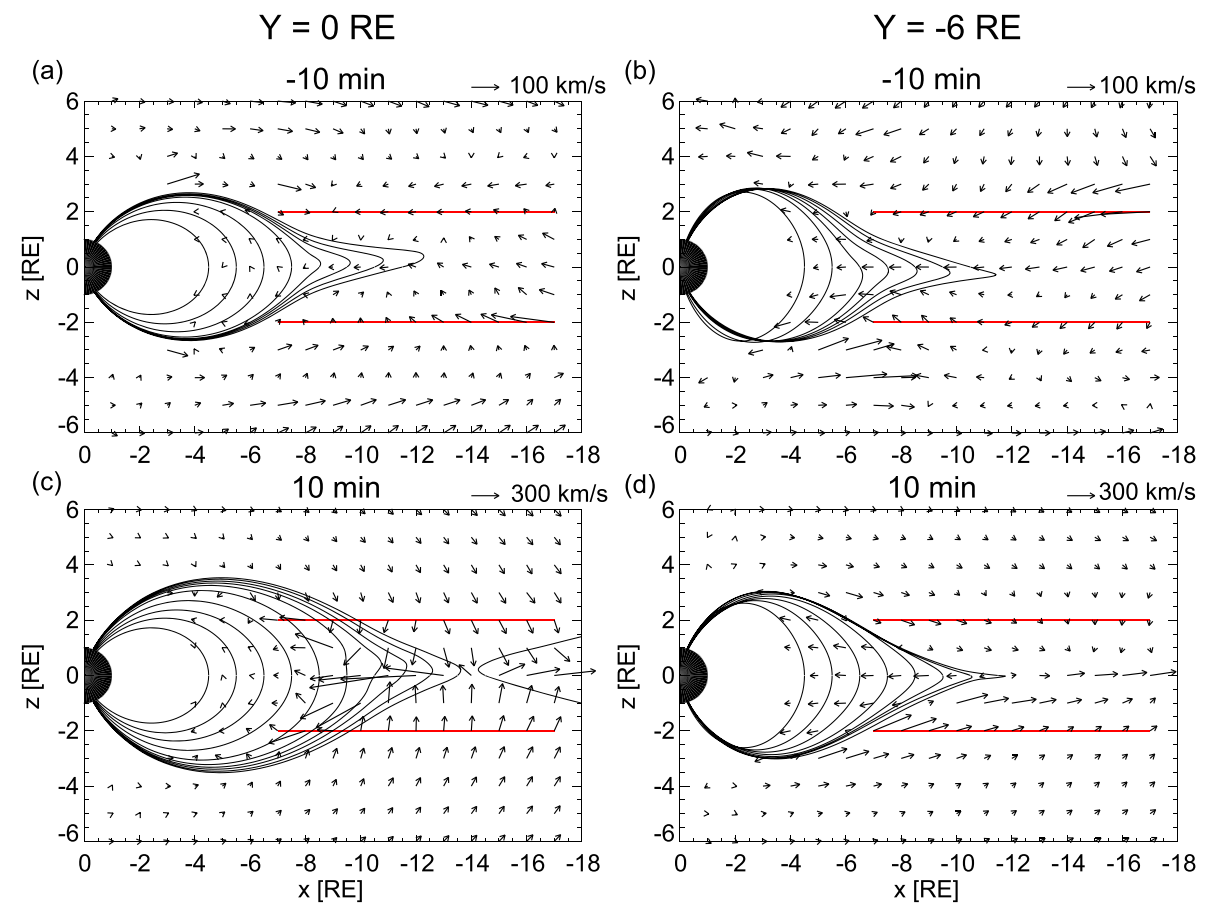

Figure 8. MHD plasma flow velocities in the $x-z$ plane $\left(V_{x z}\right)$ at (a and c) $y=0 R_{E}$ and (b and d) $y=-6 R_{E}$ at $T=-10 \mathrm{~min}$ (before the onset) and $10 \mathrm{~min}$ (after the onset).

Figure 10 shows one typical trajectory of Group B ions with the same format as Figure 9 except for the dawn to dusk electric field at $T=15 \mathrm{~min}$ (black contour) and the magnetic field lines at $T=15 \mathrm{~min}$ (black lines). The ion departed at $(-9,-5,2) R_{E}$ where the flow velocity is $(125,2.9,-53) \mathrm{km} / \mathrm{s}$ at $\mathrm{T}=10 \mathrm{~min}$. The $\mathbf{V}_{\mathrm{MHD}}$ value at the position is equivalent to $\sim 1.5 \mathrm{keV}$, and the ion has the kinetic energy of $\sim 30 \mathrm{eV}$ in the frame of the flow at the launch. After the launch, the ion moves tailward, duskward, and toward the equatorial plane. The direction of the ion velocity turns from tailward to earthward when the ion reaches the equatorial plane, and then the ion is immediately accelerated by the enhanced dawn to dusk electric field. The magnetic moment is violated between $T=13 \mathrm{~min}$ and $14 \mathrm{~min}$, which indicate that the acceleration process is nonadiabatic. Finally, the energy reaches $\sim 200 \mathrm{keV}$ within $2 \mathrm{~min}$.

\subsection{Generation Mechanisms of the Void Structure}

We found that the ions residing at the earthward most edge of the plasma sheet (Group A ions) departed the source plane before the substorm onset (Figure 7a). Before the substorm onset, $\mathbf{v}_{\mathrm{MHD}}$ is comparable to the thermal speed $\theta$ (Figure 8a). This means that the ions do not follow the background flow, so the ions direct to various directions at the launched position before the substorm onset. Just before the substorm onset, the ions already exist around the equatorial plane with energy at tens of eV. Those preexisting particles are immediately "pushed" earthward together with the generation of the dawn to dusk electric field. The acceleration process is adiabatic because the gyroradius of these low-energy ions is small. For the adiabatic acceleration, the guiding center approximation may be valid in evaluating the change of particle energy. In such case, the gain of the kinetic energy can be described as follows

$$
\frac{\mathrm{d} K}{\mathrm{~d} t}=q \mathbf{v}_{d} \cdot \mathbf{E}
$$

where $\mathbf{v}_{d}$ is the grad-B and curvature drift velocity. The energy gain associated with magnetic field changes is ignored. The ions get various energies depending on the drift velocity and the electric field that they experienced and develop the earthward most edge of the envelope of the void structure.

Most of Group B ions are launched after the substorm onset. During the substorm expansion phase, the strong equatorward and tailward flow developed in the plasma lobe (Figure $8 \mathrm{~d}$ ). The Group B ions follow the background plasma flow because $\mathbf{V}_{\mathrm{MHD}}$ dominates thermal speed $\theta$. According to the flow pattern, most 
(a)

(b)

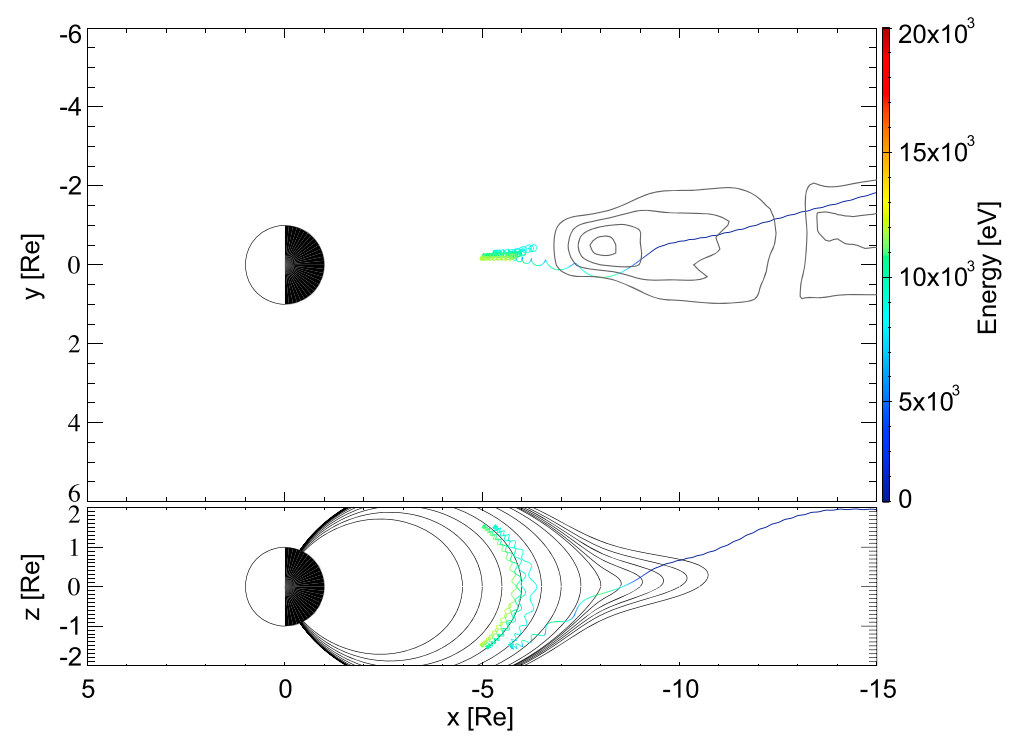

(c)

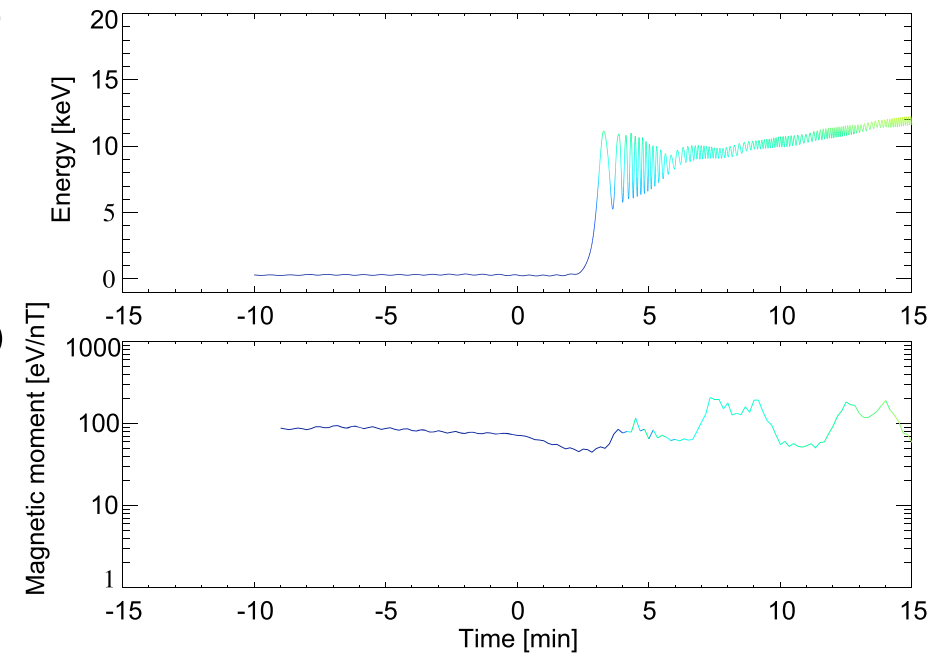

Figure 9. (a) Trajectory of the Group A ion in the $x-y$ plane with the color code and the contour lines, respectively, indicating instantaneous kinetic energy and $\left|E_{y}\right|$ at $t=0$. The interval of $E_{y}$ is $5 \mathrm{mV} / \mathrm{m}$, and the maximum $E_{y}$ (dawn to dusk) is located at $x=\sim-8 R_{E}$ near midnight. (b) Same figure as Figure 9 a but in the $x-z$ plane, and the black lines indicate the magnetic field lines at $T=0 \mathrm{~min}$. (c) The kinetic energy and (d) the magnetic moment as a function of time.

of them reach at $x<\sim-10 R_{E}$ in the equatorial region. When they reach the equatorial region, the dawn to dusk electric field is already enhanced and the radius of curvature of the magnetic field line is small. Therefore, the acceleration process of the Group B ions is basically nonadiabatic. In such a case, the energy gain of the ion can be described by the equation

$$
\frac{\mathrm{d} K}{\mathrm{~d} t}=q \mathbf{v} \cdot \mathbf{E}
$$

where $\mathbf{v}$ is the velocity of the ion and $\mathbf{E}$ is the electric field. The ions are nonadiabatically accelerated within one gyromotion; thus, the acceleration process can be treated as quasi-electrostatical acceleration traveling through the electric potential. As we stated above, the reversed plasma flow pattern brings the plasma lobe $\mathrm{O}^{+}$ions to outer region in the equatorial plane $\left(x<\sim-10 R_{E}\right)$ where an intense dawn to dusk electric field is generated. Therefore, most of the ions experience the dawn to dusk electric field and get a kinetic energy that is comparable to the electric potential. The energetic ions drift westward due to the grad-B and curvature drifts, which has the energy dependence. This causes a decrease of the threshold energy with decreasing $L$, and the value of the threshold energy at $L<\sim 5.8$ is identified at $<\sim 10 \mathrm{keV}$. 
(a)

(b)

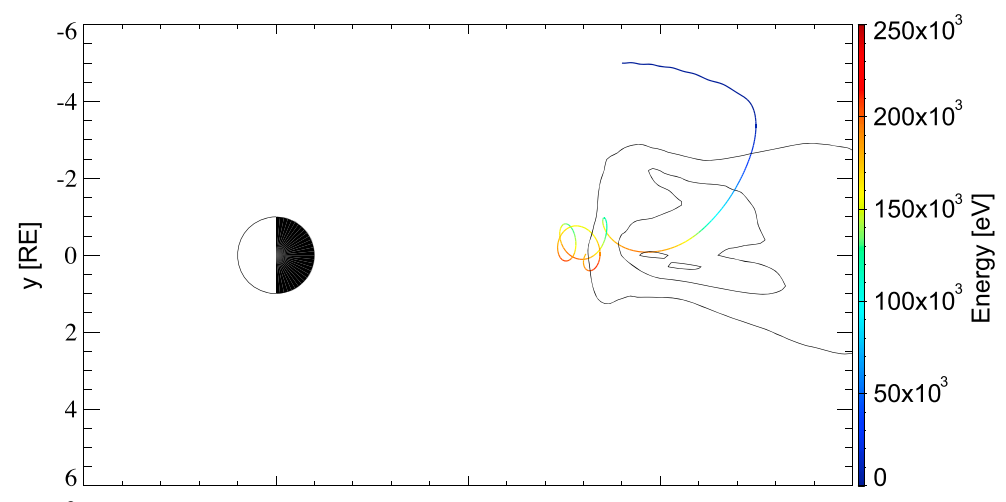

(c)
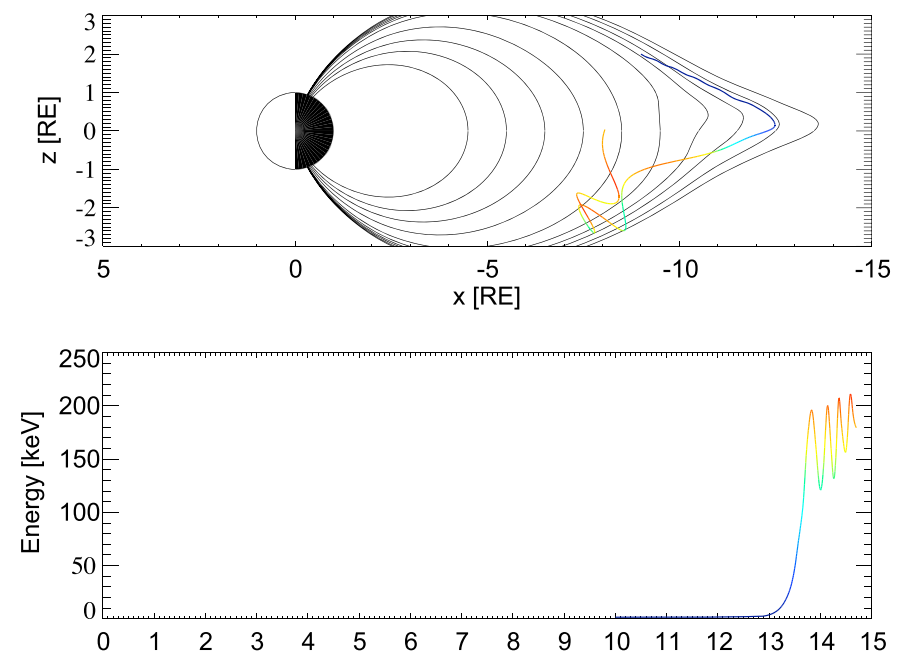

(d)

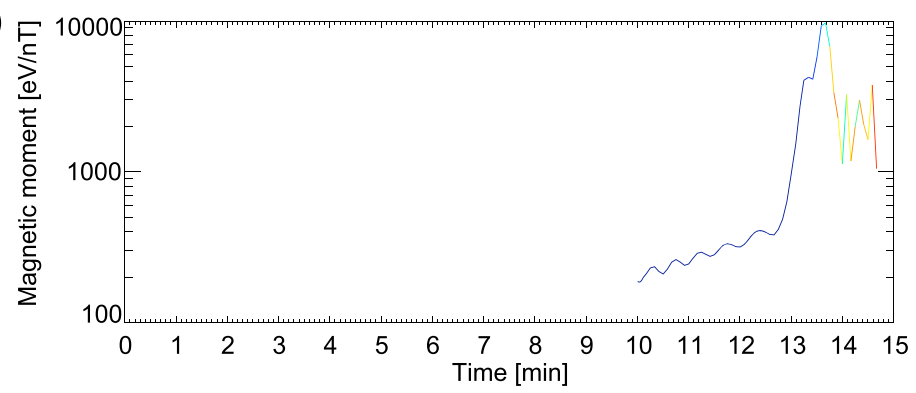

Figure 10. (a-d) Same figure as Figure 9 but for Group B ion. The black lines in Figure 10b indicate the magnetic field lines at $T=15 \mathrm{~min}$ (after the onset). Depolarized magnetic configuration is observable in Figure 10b.

We increased the initial temperature of the $\mathrm{O}^{+}$ions from $10 \mathrm{eV}$ to $10 \mathrm{keV}$. In this case, the thermal speed $\theta$ is comparable to $\mathbf{V}_{M H D}$ even during the substorm expansion phase. Figure 11 shows the energy-L spectrograms of the $\mathrm{O}^{+}$ions with initial temperature of $k T=10 \mathrm{keV}$. In Figure 11, the gap of the void structure appears to be filled. The ion, which has a large kinetic energy in the frame of $\mathrm{MHD}$ flow, can directly reach the inner region in the equatorial plane. Around the substorm onset, the dawn to dusk electric field has a peak at $x=-8 R_{E}$ near midnight and it decreases with decreasing L [Nakayama et al., 2015]. When the temperature of the $\mathrm{O}^{+}$ions in the lobe is high, the ions can directly reach the plasmasheet inner region $\left(x>\sim-8 R_{E}\right)$. They will not be highly accelerated because the potential drop between the position and at $L=6$ and at 00:00 MLT is small. Therefore, the ions are observed in the inner region without the significant energy increase and the void structure appears to be unclear.

\section{Discussion}

We reported the void structure and investigated its generation mechanisms. The HOPE observation shows that the void structure is seen in the energy- $L$ spectrogram near apogee. The void structure is clearly 
(a)

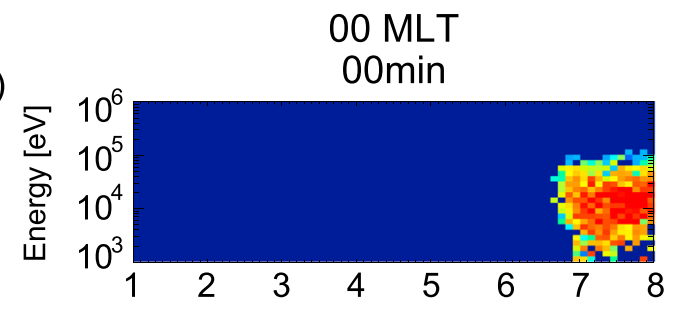

(b)

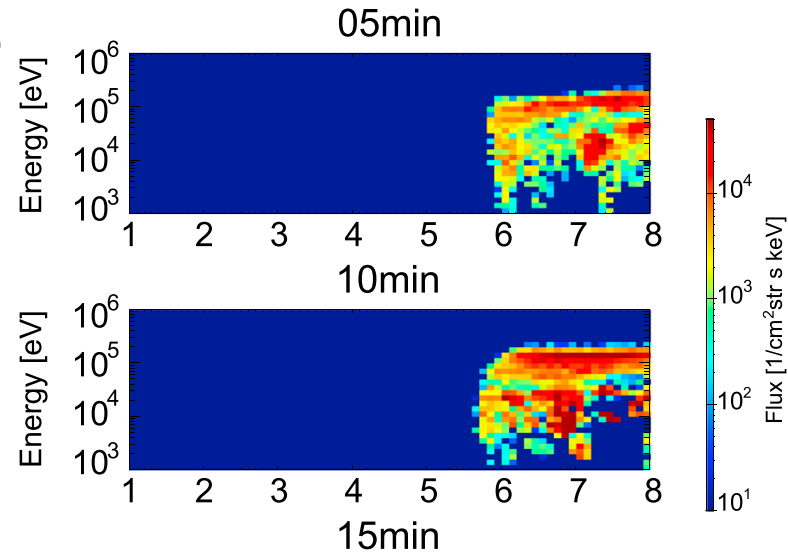

(d)

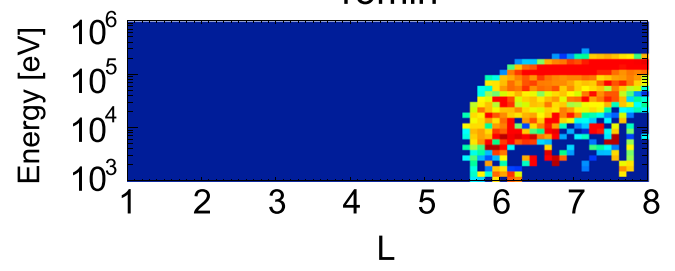

Figure 11. (a-d) Energy-L spectrograms of the simulated $\mathrm{O}^{+}$ions at 00:00 MLT in the equatorial plane with the initial temperature of $k T=10 \mathrm{keV}$. Increase of initial temperature makes the void structure unclear. identified in the $\mathrm{O}^{+}$ions but not in the $\mathrm{H}^{+}$ions. Because the void structure was observed by at least one spacecraft within $\sim 1 \mathrm{~h}$ after the SML decreases for all the cases, we speculated that the void structure is associated with ion injection. We focused on the void structure identified in the substorms when Dst $>-30 \mathrm{nT}$, because the void structure was sometimes unclear during storms (Dst $<-30 \mathrm{nT})$. As shown in Figure $11, \mathrm{O}^{+}$temperature in the plasma lobe region increases during storms and the void structure is not clearly defined.

We used the same technique as in Nakayama et al. [2015] to investigate the void structure. Our simulation reproduced the void structure well and revealed that the generation mechanisms of the void structure consist of (1) the formation of the strong equatorward and tailward plasma flow and (2) the intensive nonadiabatic acceleration. (1) Yao et al. [2015] reported that the Time History of Events and Macroscale Interactions during Substorms observations also showed a formation of

the reversed plasma flow pattern (tailward flow in the high-pressure region and earthward flow in the lowpressure region). This suggests that the formation of the intensive plasma flow pattern is a realistic phenomenon. (2) The nonadiabatic acceleration of $\mathrm{O}^{+}$ions during substorms has been reported [e.g., Delcourt, 2002; Ashour-Abdalla et al., 2009; Peroomian et al., 2011; Nosé et al., 2012; Birn et al., 2013; Nakayama et al., 2015]. Therefore, we assume that the two mechanisms are commonly occuring during substorms. One possible question is whether the void structure can be developed only with (1) the formation of the strong equatorward and tailward plasma flow or (2) the intensive nonadiabatic acceleration. (1) The strong plasma flow brings most of the plasma lobe $\mathrm{O}^{+}$ions to the plasmasheet where the curvature radius of the magnetic field line is small and the dawn to dusk electric field is strong. If it is not developed, the plasma lobe $\mathrm{O}^{+}$ions can flow into various regions, including the position where the dawn to dusk electric field is weak. Consequently, the ions are observed in the inner region without a significant energy increase and the void structure will not be formed. (2) If $\mathrm{O}^{+}$ions are adiabatically accelerated, the energy increase follows the equation (3). This indicates that low-energy ions (especially zero-energy ions) cannot gain sufficient kinetic energy because the grad-B and curvature drift velocity is small. In an extremely case, the distribution function (and the flux) of the zero-energy ions will be unchanged according to Liouville's theorem, and so the void structure will not be formed. From these points of view, we concluded that both mechanisms are essential for a development of the void structure. As we stated in section 2, the void structure does not always appear during substorms. This may be because the $\mathrm{O}^{+}$temperature in the plasmasheet region is high even before the substorm or the substorm is not strong enough to trigger the nonadiabatic acceleration for $\mathrm{O}^{+}$ions.

One notable feature of the void structure is that it is more clearly seen in the $\mathrm{O}^{+}$spectrum than the $\mathrm{H}^{+}$ spectrum. This can be explained as follows. Our analyses showed that nonadiabatic acceleration contributes to the formation of the void structure. It is widely known that nonadiabatic acceleration occurs when the Larmor radius of the charged particle is comparable to the radius of curvature of the magnetic field line 
[Sergeev et al., 1983]. Because the mass of the $\mathrm{H}^{+}$ion is one sixteenth of that of the $\mathrm{O}^{+}$ion, it is plausible that the nonadiabatic acceleration process is less effective for $\mathrm{H}^{+}$ions than for $\mathrm{O}^{+}$ions.

The wedge-like structure has been observed primarily in the dayside region at low energies (less that a few keV) [Yamauchi et al., 1996; Ebihara et al., 2001; Yamauchi et al., 2006; Ebihara et al., 2008]. Ebihara et al. [2001] suggested that the temporal variation of the ion source or the development of longitudinally narrow flow channels of ion injections can explain the wedge-like structures observed by the Viking spacecraft. Our simulation is consistent with these expectations. We showed that the source region of the injected ions is dynamically changing around the substorm onset due to the variation of background plasma flow pattern [Yao et al., 2015]. Further investigations are needed to understand the fate of the injected ions in the course of their drift motion.

The trunk-like structure is observed on the dayside during the recovery phase of magnetic storms [Zhang et al., 2015]. Zhang et al. [2015] concluded that the generation mechanism is a gap in the nightside ion source or a greatly enhanced impulsive electric field associated with an elevated geomagnetic activity. The trunk-like structure is likely the same as the wedge-like one because of the reasons listed below. (1) Both the trunk-like and the wedge-like structures are primarily observed on the dayside. (2) The ions that constitute the trunklike and the wedge-like structures probably originate from the nightside plasma sheet. As the ions drift from the nightside to the dayside, they undergo the grad- $B$ and curvature drifts that depend on energy. When the source population is longitudinally and/or radially confined in the plasma sheet, the trunk-like and the wedge-like structures appear, according to the simulation studies. A normal distribution function of ions, which decreases with energy in the nightside plasma sheet, is sufficient to explain the trunk-like and the wedge-like structures that are observed on the dayside. On the other hand, the void structure is observed on the nightside, and an unusual distribution function, which increases with energy in the nightside plasma sheet, is necessary. The unusual distribution function can be generated by nonadiabatic acceleration under the presence of a strong dawn to dusk electric field.

\section{Conclusion}

We obtained the following major conclusions.

1. During substorms, a new type of $\mathrm{O}^{+}$ion spectral feature void structure was observed by the Van Allen Probes. In total, the void structure was identified at nine substorm events between 1 January 2013 and 30 May 2013. The inner edge and the threshold energy of the void structure are usually located at $\mathrm{L}=\sim 5.5$ and $\sim 10 \mathrm{keV}$.

2. We simulated a sub-storm-time $\mathrm{O}^{+}$ion injection in the global MHD electromagnetic fields. Our simulation well reproduced the void structure observed by the Van Allen Probes. The simulation result revealed that the generation mechanisms of the void structure consist of (1) the formation of the strong equatorward flow in the low-pressure region and tailward flow in the high-pressure region and (2) the intense nonadiabatic acceleration of $\mathrm{O}^{+}$ions.

\section{References}

Computation in the present study was performed with the KDK system of Research Institute for Sustainable Humanosphere at Kyoto University as a collaborative research project. This study was supported by the KAKENHI, Grant-in-Aid for Scientific Research (B) 15H03732. Data from MHD simulation are available on request (Y. Ebihara: ebihara@rish.kyoto-u.ac.jp).
Akasofu, S. I. (1977), Physics of Magnetospheric Substorms, D. Reidel, Hingham, Mass.

Ashour-Abdalla, M., J. M. Boaqued, M. El-Alaoui, V. Peroomian, M. Zhou, R. Richard, R. Walker, A. Runov, and V. Angelopoulos (2009), A simulation study of particle enerzigation observed by THEMIS spacecraft during a substorm, J. Geophys. Res., 114, A09204, doi:10.1029/JA014126.

Ashour-Abdalla, M., M. El-Alaoui, M. L. Goldstein, M. Zhou, D. Schriver, R. Richard, R. Walker, M. G. Kivelson, and K.-J. Hwang (2011), Observations and simulations of non-local acceleration of electrons in magnetotail magnetic reconnection events, Nat. Phys., 7(4), 360-365, doi:10.1038/nphys1903.

Belian, R. D., D. N. Baker, P. R. Higbie, and E. W. Hones Jr. (1978), High-resolution energetic particle measurements at 6.6 Re, 2: High-energy proton drift echoes, J. Geophys. Res., 83, 4857-4862, doi:10.1029/JA083iA10p04857.

Birn, J., M. Hesse, R. Nakamura, and S. Zaharia (2013), Particle acceleration in dipolarization events, J. Geophys. Res. Space Physivs, 118, 1960-1971, doi:10.1002/jgra.50132.

Daglis, I. A., and W. L. Axford (1996), Fast ionospheric response to enhanced activity in geospace: lon feeding of the inner magnetotail, J. Geophys. Res., 101, 5047-5065, doi:10.1029/95JA02592.

Delcourt, D. C. (2002), Particle acceleration by inductive electric fields in the inner magnetosphere, J. Atmos. Terr. Phys., 64, 551-559, doi:10.1016/S1364-6826(02)00012-3.

Ebihara, Y., and T. Tanaka (2013), Fundamental properties of substorm time energetic electrons in the inner magnetosphere, J. Geophys. Res. Space Physics, 118, 1589-1603, doi:10.1002/jgra.50115.

Ebihara, Y., and T. Tanaka (2015), Substorm simulation: Formation of westward traveling surge, J. Geophys. Res. Space Physics, 120, doi:10.1002/2015JA021697. 
Ebihara, Y., M. Yamauchi, H. Nilsson, R. Lundin, and M. Ejiri (2001), Wedge-like dispersion of sub-keV ions in the dayside magnetosphere: Particle simulation and Viking observation, J. Geophys. Res., 106, 29,571-29,584, doi:10.1029/2000JA000227.

Ebihara, Y., L. M. Kistler, and L. Eliasson (2008), Imaging cold ions in the plasma sheet from the Equator-S satellite, Geophys. Res. Lett., 35 , L15103, doi:10.1029/2008GL034357.

Ebihara, Y., T. Tanaka, and T. Kikuchi (2014), Counter equatorial electrojet and overshielding after substorm onset: Global MHD simulation study, J. Geophys. Res. Space Physics, 119, 7281-7296, doi:10.1002/2014JA020065.

Ejiri, M. (1978), Trajectory traces of charged particles in the magnetosphere, J. Geophys. Res., 83, 4798-4810, doi:10.1029/JA083iA10p04798.

Ejiri, M., R. Hoffman, and P. H. Smith (1980), Energetic particle penetrations into the inner magnetosphere, J. Geophys. Res., 85, 653-663, doi:10.1029/JA085iA02p00653.

Fok, M. C., T. E. Moore, P. C. Brandt, D. C. Delcourt, S. P. Slinker, and J. A. Fedder (2006), Impulsive enhancements of oxygen ions during substorms, J. Geophys. Res., 111, A10222, doi:10.1029/2006JA011839.

Fu, S. Y., Q. G. Zong, T. A. Fritz, Z. Y. Pu, and B. Wilken (2002), Composition signatures in ion injections and its dependence on geomagnetic conditions, J. Geophys. Res., 107(A10), 1299, doi:10.1029/2001JA002006.

Funsten, H. O., et al. (2013), Helium, Oxygen, Proton, and Electron (HOPE) mass spectrometer for the Radiation Belt Storm Probes mission, Space Sci. Rev., 1-62, doi:10.1007/s11214-013-9968-7.

Gazey, N. G. J., M. Lockwood, M. Grande, C. H. Perry, P. N. Smith, S. Coles, A. D. Aylward, R. J. Bunting, H. Opgenoorth, and B. Wilken (1996), EISCAT/CRRES observations: Nightside ionospheric ion outflow and oxygen-rich substorm injections, Ann. Geophys., 14(1), 1032-1043, doi:10.1007/s00585-996-1032-4.

Gjerloev, J. W. (2012), The SuperMAG data processing technique, J. Geophys. Res., 117, A09213, doi:10.1029/2012JA017683.

Gkioulidou, M., A. Y. Ukhorskiy, D. G. Mitchell, T. Sotirelis, B. H. Mauk, and L. J. Lanzerotti (2014), The role of small-scale ion injections in the buildup of Earth's ring current pressure: Van Allen Probes observations of the 17 March 2013 storm, J. Geophys. Res. Space Physics, 119, 7327-7342, doi:10.1002/2014JA020096.

Gkioulidou, M., et al. (2015), Spatial structure and temp oral evolution of energetic particle injections in the inner magnetosphere during the 14 July 2013 substorm event, J. Geophys. Res. Space Physics, 120, 1924-1938, doi:10.1002/2014JA020872.

Keika, K., P. C. Brandt, S. Ohtani, D. G. Mitchell, K. Min, M. Nose, T. Obara, H. Koshiishi, and H. Matsumoto (2010), Mass-dependent evolution of energetic neutral atoms energy spectra during storm time substorms: Implication for $\mathrm{O}^{+}$nonadiabatic acceleration, J. Geophys. Res., 115, A00112, doi:10.1029/2010JA015889.

Keika, K., L. M. Kistler, and P. C. Brandt (2013), Energization of $\mathrm{O}^{+}$ions in the Earth's inner magnetosphere and the effects on ring current buildup: A review of previous observations and possible mechanisms, J. Geophys. Res. Space Physics, 118, 4441-4464, doi:10.1002/ jgra.50371.

Kessel, R. L., N. J. Fox, and N. Weiss (2013), The Radiation Belt Storm Probes (RBSP) and Space Weather, Space Sci. Rev., doi:10.1007/s11214 012-9953-6.

Konradi, A., C. L. Semar, and T. A. Fritz (1975), Substorm-injected protons and electrons and the injection boundary model, J. Geophys. Res., 80 , 543-552, doi:10.1029/JA080i004p00543.

Li, X., D. N. Baker, M. Temerin, and G. D. Reeves (1998), Simulation of dispersionless injections and subsequent drift echoes of energetic electrons associated with substorms, Geophys. Res. Lett., 25, 3763-3766, doi:10.1029/1998GL900001.

Mauk, B. H., and C. I. Meng (1983), Characterization of geostationary particle signatures based on the "injection boundary" model, J. Geophys. Res., 88, 3055-3071, doi:10.1029/JA088iA04p03055.

Mauk, B. H., N. J. Fox, S. G. Kanekal, R. L. Kessel, D. G. Sibeck, and A. Ukhorskiy (2013), Science objectives and rationale for the Radiation Belt Storm Probes mission, Space Sci. Rev., 179, 3-27, doi:10.1007/s11214-012-9908-y.

Mcllwain, C. E. (1974), Substorm injection boundaries, in Magnetospheric Physics, edited by B. M. McCormac, 143 pp., D. Reidel, Hingham, Mass,

Mitchell, D. G., P. C. Brandt, E. C. Roelof, D. C. Hamilton, K. C. Retterer, and S. Mende (2003), Global imaging of O+ from IMAGE/HENA, Space Sci. Rev., 109, 63-75, doi:10.1023/B:SPAC.0000007513.55076.00.

Moore, T. E., et al. (1997), High-altitude obseravations of the polar wind, Nature, 277, 349.

Nakayama, Y., Y. Ebihara, and T. Tanaka (2015), Generation of large-amplitude electric field and subsequent enhancement of O+ ion flux in the inner magnetosphere during substorms, J. Geophys. Res. Space Physics, 120, 4825-4840, doi:10.1002/2015JA021240.

Nosé, M., Y. Ono, S. P. Christon, and A. T. Y. Lui (2012), Revisiting the role of magnetic field fluctuations in nonadiabatic acceleration of ions during dipolarization, J. Geophys. Res., 117, A02207, doi:10.1029/2012JA017518.

Ohtani, S., et al. (2007), Cluster observations in the magnetosphere during the 18 April 2002 sawtooth event: Dipolarization and injection at $r=4.6 R_{E}$ J. Geophys. Res., 112, A08213, doi:10.1029/2007JA012357.

Peroomian, V., M. El-Alaoui, and P. C. Brandt (2011), The ion population of the magnetotail during the 17 April 2002 magnetic storm: Largescale kinetic simulations and IMAGE/HENA observations, J. Geophys. Res., 116, A05214, doi:10.1029/2010JA016253.

Reeves, G. D., R. D. Belian, and T. A. Fritz (1991), Numerical tracing of energetic particle drifts in a model magnetosphere, J. Geophys. Res., 96, 13,997-14,008, doi:10.1029/91JA01161.

Sauvaud, J. A., et al. (2004), Case studies of the dynamics of ionospheric ions in the Earth's magnetotail, J. Geophys. Res., 109, A01212, doi:10.1029/2003JA009996.

Sergeev, V. A., E. M. Sazhina, N. A. Tsyganenko, J. A. Lundblad, and F. Soraas (1983), Pitch-angle scattering of energetic protons in the magnetotail current sheet as the dominant source of their isotropic precipitation into the ionosphere, Planet. Space Sci., 31, 1147-1155, doi:10.1016/0032-0633(83)90103-4.

Smith, P. H., and R. A. Hoffman (1974), Direct observation in the dusk hours of the characteristics of the storm time ring current particles during the beginning of magnetic storms, J. Geophys. Res., 79, 966-971, doi:10.1029/JA079i007p00966.

Tanaka, T. (2015), Substorm auroral dynamics reproduced by the advanced global M-I coupling simulation, in Auroral Dynamics and Space Weather, Geophys. Monogr. Ser., vol. 215, edited by Y. Zhang and L. J. Paxton, pp. 177-192, AGU, Washington, D. C.

Tanaka, T., A. Nakamizo, A. Yoshikawa, S. Fujita, H. Shinagawa, H. Shimizu, T. Kikuchi, and K. K. Hashimoto (2010), Substorm convection and current system deduced from the global simulation, J. Geophys. Res., 115, A05220, doi:10.1029/JA014676.

Vaisberg, O. L., L. A. Avanov, J. L. Burch, and J. H. Waite (1995), Measurements of plasma in the magnetospheric tail lobes, Adv. Space Res., 18(8), 63-67, doi:10.1016/0273-1177(95)00998-1.

Yamauchi, M., R. Lundin, L. Eliasson, and O. Norberg (1996), Mesoscale structures of radiation belt/ring current detected by lowenergy ions, Adv. Space Res., 17(2), 171-174, doi:10.1016/0273-1177(95)00531-I.

Yamauchi, M., et al. (2006), Source location of the wedge-like dispersed ring current in the morning sector during a substorm, J. Geophys. Res., 111, A11S09, doi:10.1029/2006JA011621. 
Yao, Y., Y. Ebihara, and T. Tanaka (2015), Sudden pressure enhancement and tailward retreat in the near-Earth plasma sheet: THEMIS observation and MHD simulation, J. Geophys. Res. Space Physics, 120, 201-211, doi:10.1002/2014JA020482.

Zaharia, S., C. Z. Cheng, and J. R. Johnson (2000), Particle transport and energization in association with substorms, J. Geophys. Res., 105, 18,741-18,752, doi:10.1029/1999JA000407.

Zhang, J.-C., et al. (2015), "Trunk-like" heavy ion structures observed by the Van Allen Probes, J. Geophys. Res. Space Physics, 120, 8738-8748, doi:10.1002/2015JA021822. 